ISSN: 2224-0616

Int. J . Agril. Res. Innov. \& Tech. 4 (1): 98-101, J une, 2014

Available online at http:// www.ijarit.webs.com

\title{
IMPROVEMENT OF FINISHING ANTIFRICTION TREATMENT WITHOUT ABRASIVE OF THE RUBBING PARTS SURFACES OF AGRICULTURAL MACHINERIES
}

\author{
I.V. Shepelenko1, V.V. Cherkun², A. Warouma ${ }^{3 *}$ \\ Received 24 March 2014, Revised 10 June 2014, Accepted 28 June 2014, Published online 30 June 2014
}

\begin{abstract}
The wear of machines and mechanisms after rubbing is a major concern. The costs of manufacturing and restoration parts for agricultural machinery are enormous such as the trunnions pinions of hydraulic pumps. Finishing treatment antifriction without abrasive (FTAA) is the existing method of manufacturing and restoration, but it has disadvantages like low work efficiency and the frequent replacement of the instrument. That is why a new method of FTAA parts type "tree" has been developed called vibratory finishing treatment antifriction without abrasive, (VFTAA) method. The study was conducted at the laboratory of the State Technical University of Kirovograd (Ukraine) where turn 16K20, the profilograph-profilometer "Talysurf-5", the scanning electron microscope REM-106I, friction machine MI-1M and the stand KI-28097-02M were used respectively for machining, study of micro relief before and after the VFTAA, microstructure, wear resistance and the determination of the break-in period of parts. The results showed that the VFTAA helped reduce the roughness $\mathrm{Ra}$ of the samples studied by half compared to the samples processed by polishing and 1.3 times compared to those treated with the FTAA, the break-in period has been reduced four times, this leads to an increase in the life of the hydraulic pump. This technology can be recommended for manufacturing and repair of hydraulic units of agricultural machineries.
\end{abstract}

Keywords: Finishing Treatment, Abrasive, Trunnions Pinions, Wear Resistance, Rotation Speed

${ }^{1}$ Department of Agricultural Machinery Operating and Repair, National Technical University of Kirovograd, Ukraine

${ }^{2}$ Department of Mechanic and Technology, Agrotechnological University of State Tavri, Ukraine

${ }^{3}$ Department of Rural Engineering \& Water and Forests, University of Maradi, Niger

*Corresponding author's email: warouma@yahoo.com (A. Warouma)

\section{Introduction}

The wear of machines and mechanisms after friction is one of the most pressing issues of our time. Manufacturing and restoration costs of worn parts of agricultural machineries are enormous due to rubbing. They are even higher for the parts such as pins sprockets hydraulic pumps that require high precision machining. The existing technologies for manufacturing and repairing of high precision parts require a long period of machining in order to increase their lifespan (Garkunov, 2009; Fedorenko et al., 2011). These costs can be reduced significantly by using rational methods based on tribotechnic. These methods must include the FTAA which is a finishing treatment of surfaces parts whose essence consists that the parts of the sliding surfaces should be covered with a thin layer of brass, bronze or copper by using the phenomenon of metal transfer during the rubbing (Kuzharov and Kuzharov, 2011). A coating of ductile metal with a thickness of 50 to $500 \mathrm{~nm}$ is applied to the rubbing surfaces of different machine parts. The FTAA is applied in order to reduce the intensity of wear, increasing the crack resistance of the rubbing surfaces and the intensification of the training process of films protection during the break-in period, after manufacturing or restoration of parts (Balabanov et al., 2010; Katkov, 2009).

However, these traditional methods of FTAA have poor performance (Bystrov, 2011); this stops their widespread use as a finishing treatment of parts in industrial conditions. Among the disadvantages of existing process of FTAA, in addition to inadequate work performance, we can mention the frequent replacement of the instrument because of its irregular wear.

The irregular wear of the instrument can only be removed when it rotates during the process of FTAA. Performance of FTAA can be improved by increasing the speed of the relative movement of the couple "tool-parts" not by increasing the speed of rotation of the part, but by the creation of the longitudinal oscillations of the instrument when machining. This will accelerate the FTAA without compromising the quality of the process. 
By considering these lacks of performances, the machining tool must have a movement of rotation and an oscillation. For that reason, it was developed for the first time a method of FTAA of parts type "tree" with the use of vibration called vibratory finishing treatment antifriction without abrasive (VFTAA) method.

Thus, the objective of this work is to study the influence of VFTAA on the quality of the machined surfaces, the structure, physico mechanical properties and antifriction of the surface layer journals gears hydraulic pumps agricultural machineries.

\section{Materials and Methods}

The study was conducted at the laboratory of the State Technical University of Kirovograd, Ukraine between 2010 and 2012.

The VFTAA parts took place on a turn 16K20 by using the schema developed (Fig. 1), the device (Fig. 2) and the surface active medium with the following plans: instrument pressure $\mathrm{P}=6 \mathrm{MPa}$; speed sliding of the instrument, $\mathrm{Vsl}=1,82 \mathrm{~m} / \mathrm{s}$; ratio of the number of strokes of the instrument and the speed of the instrument, $\mathrm{n}_{\partial \varepsilon . x .} / \mathrm{n}_{\partial}=57$;

the value of oscillation of the instrument ${ }^{\ell_{0}}=$ $7.12 \mathrm{~mm}$; longitudinal movement of feed, $\mathrm{S}=1$ $\mathrm{mm} /$ rotation.

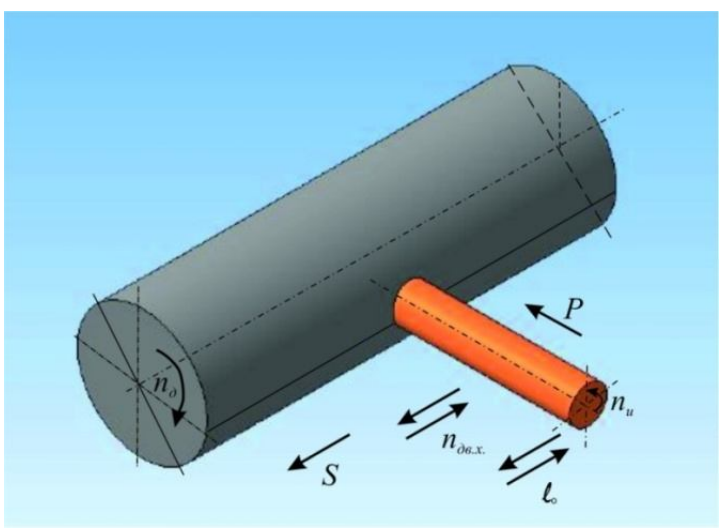

Fig.1 Diagram of the implementation of vibratory finishing treatment antifriction without abrasive: $\mathrm{P}$ pressure of the instrument; $\mathrm{n}_{\partial}$ - speed of rotation of the part, $\mathrm{n}_{u}$ - speed of rotation of the instrument; $\mathrm{n} \partial_{\varepsilon . x}$. Number of strokes of the instrument, S - longitudinal feed movement of the instrument, $l_{o}$ - oscillation of the instrument.

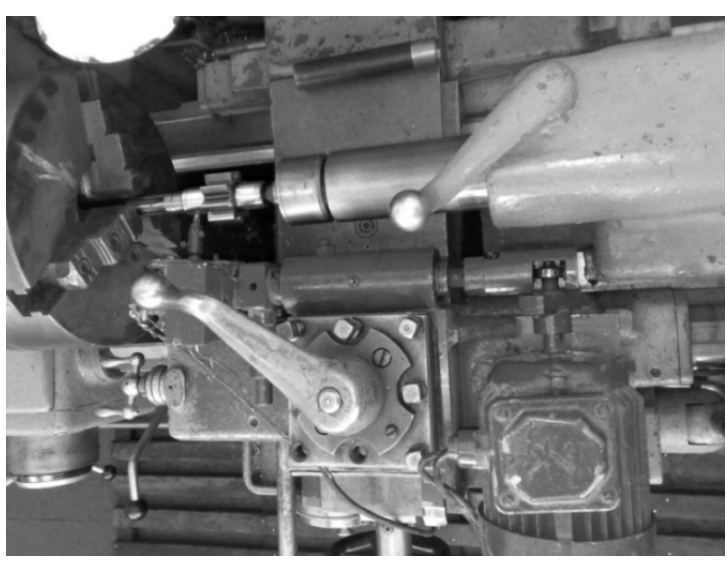

Fig. 2. Vibratory finishing treatment antifriction without abrasive of trunnions pinions of hydraulic pumps of agricultural machineries

The study of the surface of the micro relief before and after the VFTAA was realized by using a profilograph-profilometer "Talysurf- 5 ", the microstructure of the carburized $18 \mathrm{CrMnTi}$ samples were investigated by the scanning electron microscope REM-106I, the wear resistance with machine friction MI- $1 \mathrm{M}$. The stand KI-28097-02M was used for doing the speed tests of hydraulic pumps.

In order to determine the break-in period of the main components of pumps NSH50A-3 and NSH100A-3, the trunnions pinions treated with existing and proposed technologies have been investigated on the stand. The power of electric motor transmitted on the training of the hydraulic pump has been analyzed in terms of different types of treatment in order to assess the duration of running.

\section{Results}

The results showed that to obtain a high-quality coating, it is necessary that the initial surface roughness of the steel is not less than $1.25 \mathrm{Ra}$. During the machining process, the VFTAA reduced the roughness $\mathrm{Ra}$ of the samples studied twice compared to the samples treated by polishing, and 1.3 times relative to FTAA (Fig.3). 


\section{Ra, $\mu \mathbf{m}$}

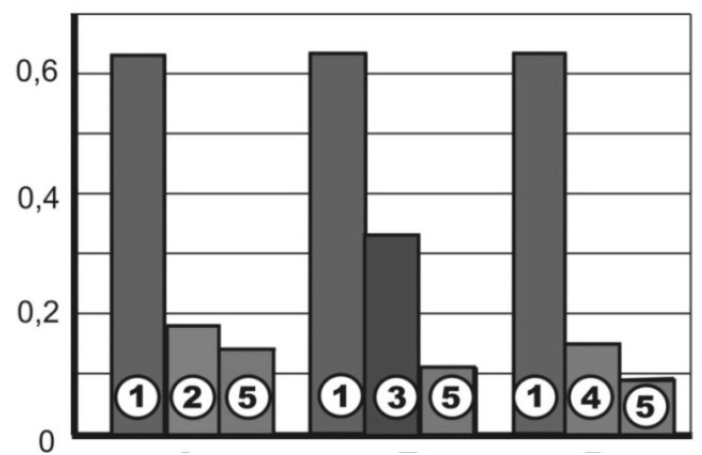

Fig. 3. Variation of roughness parameter of samples during machining in different types of finishing treatment: A - finish turning (1) polish (2) and breakin (5); B - finish turning (1) FTAA (3) and running (5); $\mathrm{C}$ - finish turning (1) VFTAA (4) and running (5).

The VFTAA reduced machining time, improved the break-in process of the rubbing couple "steel bronze" and reduced considerably the intensity of initial wear of the surface layers (Fig. 4) compared to samples treated with a finish turning and a polishing by obtaining a uniform and dense coating.

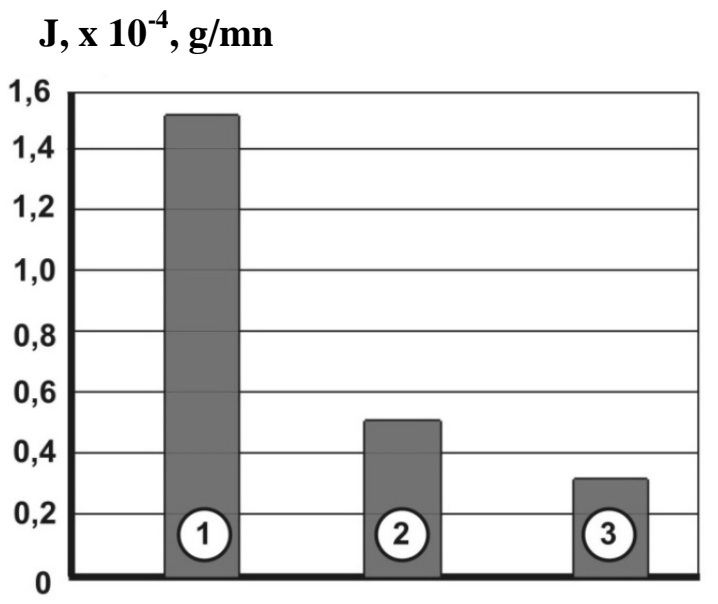

Fig. 4. Diagram intensity of initial wear J in different types of finish: 1 - finish by turning and polishing; 2 finishing turning and FTAA; 3 - finishing turning and VFTAA.

Use of VFTAA reduced the total wear of the joint "trunnion-hub" (Fig. 5) and the friction coefficient (Fig. 6).

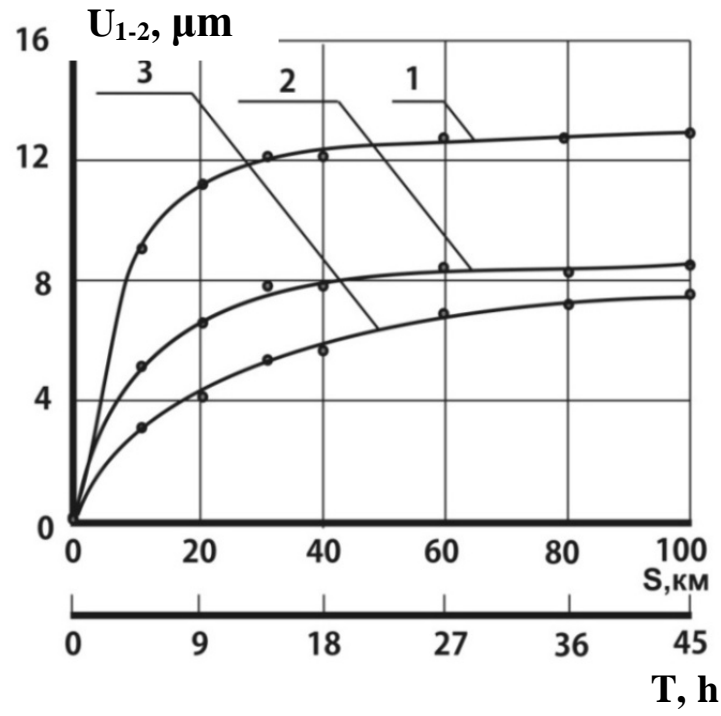

Fig. 5. Dependence total wear of the joint U1-2 depending on the path S and time $\mathrm{T}$ of rubbing during different types of finishing treatment: 1 - polishing, 2 FTAA, 3 - VFTAA.

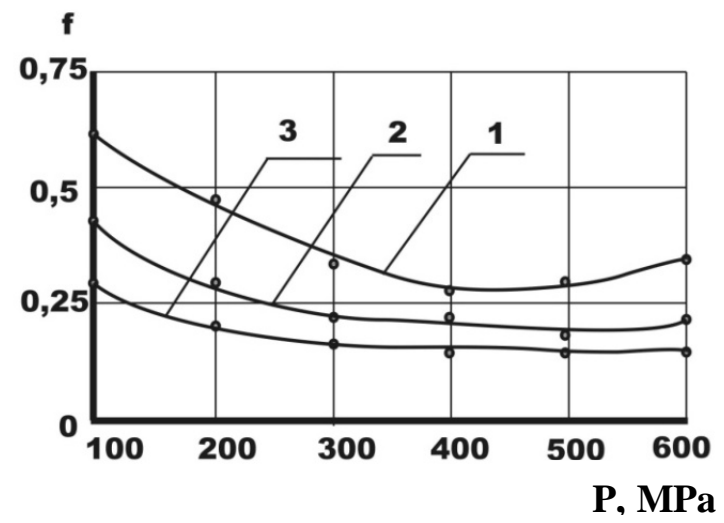

Fig. 6. Dependence of the rubbing coefficient (f) according to the loads $(\mathrm{P})$ according to the different processing methods: 1 - polishing, 2 - FTAA, 3 VFTAA.

The dependence of the break-in period of trunnions pinions of hydraulic pumps treated with different technologies according to the energy function transmitted by the electric motor to the hydraulic pump shown in Fig. 7. 


\section{$\mathbf{N}, \mathbf{K w}$}

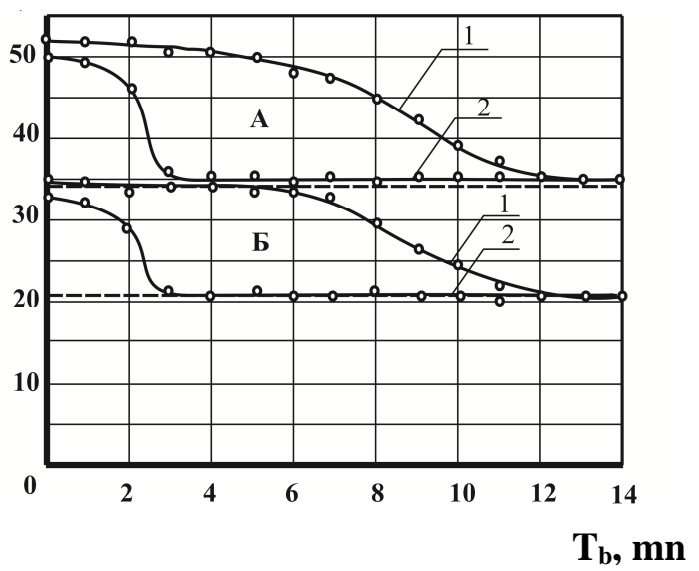

Fig. 7. Dependence of the break-in period $\left(\mathrm{T}_{\mathrm{b}}\right)$ of trunnions of hydraulic pumps (NSH100A-3 and NSH50A-3) according to the force transmitted and by using different technologies: 1 - existing technology; 2 the proposed technology with the adoption of the VFTAA.

Testing stand revealed that the break-in period, characterized by the stabilization of energy consumption by the electric motor of the stand during the application of existing technology was 12 minutes, while the technology by using the VFTAA of trunnions pinions of hydraulic pumps was 3 minutes.

\section{Discussion}

The FTAA has a low yield compared to the proposed technology: VFTAA. This low yield is explained by the fact that the speed of the relative movement of the tool and part is performed only by the rotation of the part.

The VFTAA reduced roughness $\mathrm{Ra}$ of the samples studied twice compared to the samples treated by polishing, and 1.3 times according to FTAA. This reduction is due to the more intensive rubbing brass in cavities of micro ledges and flattening the tops of micro ledges.

With the use of VFTAA, the break-in period of trunnions pinions of hydraulic pumps was 3 minutes against 12 minutes with FTAA. Therefore, this leads to the reduction of wear of the friction couple during the break-in period, to the stabilization of play in the joint, and consequently to an increase in the life span of the hydraulic pump during operation.
The studies conducted on the FTAA by Garkunov (2009) and Katkov (2009) gave successively the periods of running parts: 9 and 11 minutes, which are significantly lower than which are obtained by the developed technology (3 min).

\section{Conclusion}

The technology developed of VFTAA of trunnions pinions reduced significantly the period running of hydraulic pumps, the cost of recovery, and improved the life span of hydraulic pumps and can be recommended like at the time of manufacturing, as at the time of repair of hydraulic units of agricultural machineries. The use of coating technology with TVFASA allows in perspective the replacement of parts of nonferrous alloys, steel and cast iron with antifriction coating.

\section{References}

Balabanov, I.V., Bolgov, V.Y. and Ichenko, S.A. 2010. Application by friction nanoscale of antifriction coatings on parts nanotechnology, ecology, production. 1 (3): 104-107.

Bystrov, V. 2011. Use of devices for mechanical input by friction of wear resistant coatings in the repair mass conditions /Invention. 11 (3): 29-34.

Fedorenko, V.F., Erohin, M.N., Balabanov, V.I., Buklagin, D.S., Golubev, G.I. and Ishchenko, S.A. 2011. Nanotechnologies and nanomaterials in agriculture: ed.sci. / M.: FNGU "Rosinformagroteh". 312p.

Garkunov, D.N. 2009. Finishing treatment antifriction without abrasive (FTAA) parts of the friction surfaces of the parts PRM (Preparation. Restoration. Modernization). 3: 36-41.

Katkov, D.S. 2009. Increase of longevity of friction parts for agricultural machineries by using tribological methods / Saratov, 251p.

Kuzharov, A.S. and Kuzharov, A.A. 2011 More and a little differently on the plating of metals, the FTAA and the nonwear. In: Proc. Samara Scientific Center of the Russian Academy of Sciences. 4 (3): 772775. 